Article

\title{
The Pharmaceutical Ability of Pistacia lentiscus L. Leaves Essential Oil Against Periodontal Bacteria and Candida sp. and Its Anti-Inflammatory Potential
}

\author{
Egle Milia $^{1, *(\mathbb{D})}$, Marianna Usai ${ }^{2}$, Barbora Szotáková ${ }^{3}\left(\mathbb{D}\right.$, Marie Elstnerová $^{3}$, Věra Králová ${ }^{4}$, \\ Guy D'hallewin ${ }^{5}$, Ylenia Spissu ${ }^{5}$ (D) Antonio Barberis ${ }^{5}$ (D), Mauro Marchetti ${ }^{6}$, \\ Antonella Bortone ${ }^{7}$, Vincenzo Campanella ${ }^{8}$, Giorgio Mastandrea ${ }^{9}$, Lenka Langhansová ${ }^{10}$ and \\ Sigrun Eick 11,*iD
}

1 Department of Medicine, Surgery and Experimental Science, University of Sassari, Viale San Pietro 43, 07100 Sassari, Italy

2 Department of Chemistry and Pharmacy, University of Sassari, Via Rolando, 07100 Sassari, Italy; dsfusai@uniss.it

3 Faculty of Pharmacy, Charles University, Akademika Heyrovského 1203, 50005 Hradec Králové, Czech Republic; szotakova@faf.cuni.cz (B.S.); elstnerovam@faf.cuni.cz (M.E.)

4 Faculty of Medicine, Charles University, Šimkova 870, 50003 Hradec Králové, Czech Republic; kralovav@lfhk.cuni.cz

5 National Research Council-Institute of Sciences of Food Production, Traversa La Crucca 3, Loc. Baldinca, 07100 Sassari, Italy; guy.dhallewin@cnr.it (G.D.); yspissu@uniss.it (Y.S.); antonio.barberis@cnr.it (A.B.)

6 National Research Council-Institute of Biomolecular Chemistry, Traversa La Crucca 3, Loc. Baldinca, 07100 Sassari, Italy; mauro@ss.cnr.it

7 Dental Unite, Department of Surgery, Azienda Ospedaliero Universitaria, 07100 Sassari, Italy; antonella.bortone@aousassari.it

8 Department of Clinical and Translational Medicine, University of Rome, Tor Vergata, 00133 Rome, Italy; vincenzo.campanella@uniroma2.it

9 Department of Biomedical Science, University of Sassari, Viale San Pietro 43/C, 07100 Sassari, Italy; 30050744@studenti.uniss.it

10 Institute of Experimental Botany, Czech Academy of Sciences, Rozvojová 263, 16502 Prague, Czech Republic; langhansova@ueb.cas.cz

11 Department of Periodontology, School of Dental Medicine, University of Bern, Freiburgstrasse 7, 3010 Bern, Switzerland

* Correspondence: emilia@uniss.it (E.M.); sigrun.eick@zmk.unibe.ch (S.E.); Tel.: +39-79-228437 (E.M.); +41-31-632-25-42 (S.E.)

Received: 30 April 2020; Accepted: 23 May 2020; Published: 26 May 2020

\begin{abstract}
Background: Given the increasing request for natural pharmacological molecules, this study assessed the antimicrobial capacity of Pistacia lentiscus L. essential oil (PLL-EO) obtained from the leaves of wild plants growing in North Sardinia (Italy) toward a wide range of periodontal bacteria and Candida, including laboratory and clinical isolates sp., together with its anti-inflammatory activity and safety. Methods: PLL-EO was screened by gas chromatography/mass spectrometry. The minimal inhibitory concentration (MIC) was determined. The anti-inflammatory activity was measured by cyclooxygenase (COX-1/2) and lipoxygenase (LOX) inhibition, while the antioxidant capacity was determined electro-chemically and by the MTT assay. The WST-1 assay was used to ascertain cytotoxicity toward four lines of oral cells. Results: According to the concentrations of terpens, PLL-EO is a pharmacologically-active phytocomplex. MICs against periodontal bacteria ranged between 3.13 and $12.5 \mu \mathrm{g} / \mathrm{ml}$, while against Candida sp. they were between 6.25 and $12.5 \mu \mathrm{g} / \mathrm{mL}$. Oxidation by COX-1/2 and LOX was inhibited by $80 \%$ and $20 \% \mu \mathrm{g} / \mathrm{mL}$ of the oil, respectively. Antioxidant activity seemed negligible, and no cytotoxicity arose. Conclusions: PLL-EO exhibits a broad-spectrum activity against periodontal bacteria and Candida, with an interesting dual inhibitory capacity toward COX-2 and LOX inflammatory enzymes, and without side effects against oral cells.
\end{abstract}


Keywords: oral health care products; cyclooxygenase; lipoxygenase; periodontal disease; Candida albicans; Candida glabrata; medicinal herbs

\section{Introduction}

Periodontal and peri-implant diseases, in addition to Candida spp. infections, are among the most common and recalcitrant oral plights that evoke immuno-inflammatory responses. Evidence is provided that periodontitis is associated with an imbalance of the oral microbiome [1] and other risk factors such as smoking, hyperglycaemia, and xerostomia [2,3]. Within the oral microbiome imbalance, Gram-negative, proteolytic, and anaerobic biofilm-forming bacteria, namely Porphyromonas gingivalis, Tannerella forsythia, and Fusobacterium nucleatum, may become dominant, settle gingival margins, and pave the way for chronic multifactorial disease $[1,4,5]$, whereas Candidiasis by Candida albicans and Candida glabrata turns out to be among the predominant infective-agents in immunocompromised patients [6]. Following epithelial cell harming by pathogenic agents, the inflammatory process sets off, and pro-inflammatory cytokines are released to start the healing process $[1,7,8]$. However, under these physio-pathological conditions, severe and recurrent inflammation can be concomitant with periodontitis and oral Candidiasis [9,10], and may contribute to deleterious consequences. Lasting oxidation of arachidonic acid by cyclooxygenases (COX-1 and COX-2) and lipoxygenase (5-LOX) leads to the accumulation of prostaglandins and leukotrienes [11,12]. Among these oxidized products, prostaglandine $\mathrm{E}_{2}\left(\mathrm{PGE}_{2}\right)$ and related lipid mediators activate immune cells and stimulate pro-inflammatory and pro-coagulant responses. Furthermore, the activation of phagocytes within the inflammation process burst oxygen consumption, jeopardizing severely cell redox homeostasis by rising reactive oxygen species (ROS) [13]. Within this framework, the repair of the infected tissue is hindered, favouring the outbreak of chronic multifactorial diseases [14-17].

With the intent to antagonise recurrent oral inflammation, oral antiseptics are often administered. However, several synthetic molecules, such as chlorhexidine digluconate, largely used in commercial oral antiseptics, have shown high cytotoxicity against human fibroblasts and osteoblasts [18-21]. Time-dependent toxicity was demonstrated in fibroblasts viability after exposure to chlorhexidine $>0.001 \%$ [19], and cellular damages were raised by the presence of other chemicals in the mixture attesting an increase in toxicity by synthetic substances [21]. On the other hand, if employing systemic non-steroidal anti-inflammatory drugs (NSAIDs) or even steroids, gastrointestinal and cardiac toxicity as well as nephrotoxic side effects can occur [22-24].

Thus, new pharmacological molecules differently acting, with a broad-microbial targeting activity, and able to constraint also the inflammation process without producing side effects to the host, are needed [25]. In this regard, plant essential oils (EO) are potential candidates, even though, according to concentration, toxicity towards cells has been reported $[13,26]$. Essential oils are phytocomplexes composed of several chemical classes, among which polyphenols are acquiring an increasing interest due to their functional properties [27-32]. Concerning these phytocomplexes, Pistacia lentiscus L. (PLL), belonging to the Anacardiaceae family, is a wild-growing species of the Mediterranean basin particularly diffused in Sardinia (Italy), with leaf-EO rich in terpenoids [33]. In popular medicine, PLL plant and processed products (leaf-EO, drupe oil, resin) have been largely employed as oral antiseptic, anti-inflammatory, analgesic, and healing agents [33,34]. Quartu et al. (2012) [35] reported that PPL-leaf-EO promoted the biosynthesis of highly polyunsaturated fatty acids in mice, lowered the expression of COX-2, and protected brain tissue from ischemia, while Orrù et al. (2017) [36], employing PPL-drupe oil, evidenced a selective growth inhibition towards some pathogenic bacteria of the oral cavity.

Given the above considerations, after determining the major constituents of PLL leaf essential oil (PLL-EO), the purpose of this study was to evaluate its capacity for some functional implications regarding the periodontal disease and Candidiasis. With this intention, we assessed the inhibitory 
ability to PLL-EO to a wide range of microorganisms and clinical species involved in these infections, in addition to its anti-inflammatory strength. Further, we tested potential cytotoxicity of PLL-EO against the periodontal ligament fibroblasts (PDLF), gingival fibroblasts (GF), gingival keratinocytes (GK), and dysplastic oral keratinocytes (DOK).

The hypothesis of the present study was that PLL-EO has anti-microbial and anti-inflammatory activities without negatively interfering with human cells viability.

\section{Results}

\subsection{Essential Oil Yield and Chemical Fingerprinting}

Following hydro-distillation, the yield of PLL-EO was about $0.41 \%(\mathrm{w} / \mathrm{w})$. The GC-MS analyses identified 64 constituents, which represented $97.28 \%$ of the total components (Table 1). Among these, 17 components made up 1\% of the total. GC-MS identified $\alpha$-pinene and terpinen-4-ol as the main constituents of PLL-EO with a concentration of $16.89 \%$ and $16.49 \%$, respectively. The monoterpenes, limonene and $\beta$-myrcene, represented $3.89 \%$ and $0.87 \%$, respectively, while the sesquiterpenes, (Z)-caryophyllene, and (E)-caryophyllene, embodied $1.39 \%$ and $0.07 \%$, respectively.

Table 1. Chemical composition of Pistacia lentiscus L. essential oil from fresh leaves.

\begin{tabular}{ccccc}
\hline RI apol Sper & RI apol Lett & Constituents & $\%$ & ID \\
\hline 924 & 927 & tricyclene & $0.24 \pm 0.01$ & MS-RI \\
930 & 931 & $\alpha$-thujene & $0.23 \pm 0.01$ & Std \\
939 & 937 & $\alpha$-pinene & $16.89 \pm 0.15$ & Std \\
955 & 956 & camphene & $1.04 \pm 0.04$ & Std \\
977 & 975 & sabinene & $7.73 \pm 0.11$ & Std \\
981 & 979 & $\beta$-pinene & $4.30 \pm 0.05$ & Std \\
992 & 991 & $\beta$-myrcene & $0.87 \pm 0.02$ & Std \\
1005 & 1003 & $\alpha$-phellandrene & $7.39 \pm 0.12$ & Std \\
1015 & 1017 & $\alpha$-terpinene & $4.79 \pm 0.04$ & Std \\
1025 & 1025 & p-cymene & $1.10 \pm 0.03$ & Std \\
1027 & 1029 & limonene & $3.89 \pm 0.07$ & Std \\
1031 & 1030 & $\beta$-phellandrene & $4.71 \pm 0.05$ & MS-RI \\
1035 & 1037 & Cis- $\beta$-ocimene & $0.24 \pm 0.02$ & MS-RI \\
1056 & 1056 & isoamyl isobutyrate & $0.55 \pm 0.02$ & MS-RI \\
1056 & 1056 & 2 -methylbuthyl butanoate & $0.18 \pm 0.01$ & Std \\
1064 & 1060 & $\gamma$-terpinene & $6.30 \pm 0.09$ & Std \\
1087 & 1089 & terpinolene & $3.25 \pm 0.02$ & MS-RI \\
1090 & 1091 & p-cymenene & $0.12 \pm 0.01$ & MS-RI \\
1094 & 1094 & isopentyl isivalerate & $0.13 \pm 0.01$ & MS-RI \\
1108 & 1108 & n-amyl isovalerate & $0.04 \pm 0.01$ & MS-RI \\
1115 & 1117 & fenchol & $0.11 \pm 0.01$ & MS-RI \\
1147 & 1144 & Cis- $\beta$-terpineol & $0.13 \pm 0.01$ & Std \\
1166 & 1169 & borneol-endo & $0.16 \pm 0.01$ & Std \\
1181 & 1177 & terpinen-4-ol & $16.49 \pm 0.18$ & MS-RI \\
1187 & 1189 & $\alpha$-terpineol & $3.98 \pm 0.07$ & MS-RI \\
1194 & 1199 & $\gamma$-terpineol & $0.07 \pm 0.01$ & MS-RI \\
1242 & 1238 & isopentyl hexanoate & $0.24 \pm 0.02$ & MS-RI \\
1247 & 1247 & 2 -methylbuthyl hexanoate & $0.17 \pm 0.01$ & Std \\
1258 & 1253 & piperitone & $0.05 \pm 0.01$ & Std \\
1294 & 1294 & 2 -undecanone & $0.85 \pm 0.03$ & MS-RI \\
1355 & 1351 & $\alpha$-cubebene & $0.05 \pm 0.01$ & Std \\
1378 & 1377 & $\alpha$-copaene & $0.24 \pm 0.01$ & MS-RI \\
1380 & 1382 & $\beta$-maaliene & $0.33 \pm 0.02$ & MS-RI \\
1407 & 1409 & Z)-caryophyllene & $1.39 \pm 0.06$ & MS-RI \\
1419 & 1419 & $($ E)-caryophyllene & $0.07 \pm 0.01$ & Std \\
\hline & & &
\end{tabular}


Table 1. Cont.

\begin{tabular}{ccccc}
\hline RI apol Sper & RI apol Lett & Constituents & $\mathbf{\%}$ & ID \\
\hline 1457 & 1460 & alloaromadendrene & $0.14 \pm 0.01$ & Std \\
1480 & 1480 & $\gamma$-muurolene & $0.57 \pm 0.03$ & Std \\
1485 & 1485 & $\alpha$-amorfene & $0.07 \pm 0.01$ & MS-RI \\
1486 & 1485 & germacrene D & $2.73 \pm 0.11$ & MS-RI \\
1497 & 1499 & Cis-dihydro apofarnesal & $0.14 \pm 0.01$ & MS-RI \\
1502 & 1500 & $\alpha$-muurolene & $0.53 \pm 0.02$ & Std \\
1509 & 1506 & $\beta$-bisabolene & $0.19 \pm 0.01$ & MS-RI \\
1521 & 1523 & $\delta$-cadinene & $1.43 \pm 0.04$ & MS-RI \\
1535 & 1535 & Trans-cadina-1(2),4-diene & $0.15 \pm 0.01$ & Std \\
1539 & 1539 & $\alpha$-cadinene & $0.07 \pm 0.01$ & Std \\
1552 & 1552 & Cis-muurol-5-en-4- $\beta$-ol & $0.07 \pm 0.01$ & Std \\
1535 & 1535 & Trans-cadin-4-en-7-ol & $0.31 \pm 0.02$ & Std \\
1639 & 1640 & epi- $\alpha$-cadinol & $1.22 \pm 0.08$ & Std \\
1644 & 1646 & $\alpha$-muurolol & $0.94 \pm 0.04$ & Std \\
1648 & 1652 & cedr-8(15)-en-9- $\alpha$-ol & $0.12 \pm 0.01$ & Std \\
& & & 96.96 &
\end{tabular}

* ID = Identification methods: MS by comparison of the mass spectrum with those of the computer mass libraries Adams (NIST 11) and by interpretation of the mass spectra fragmentations; RI by comparison of retention index with those reported in literature; Std by comparison of the retention time and mass spectrum of available authentic standards; MS identification of mass spectrum. No-polar column ZB-5. Data are the mean of three replicates.

\subsection{Minimal Inhibitory Concentrations Against Oral Bacteria and Candida sp.}

The MIC of PLL-EO (Table 2) against oral bacteria involved in periodontal diseases ranged between $3.13 \mu \mathrm{g} / \mathrm{mL}$ (P. gingivalis, T. forsythia) and $12.5 \mu \mathrm{g} / \mathrm{mL}$ (S. gordonii). Regarding the effects on Candida sp., the recorded values ranged from $6.25 \mu \mathrm{g} / \mathrm{mL}$ for $C$. glabrata strains to $12.5 \mu \mathrm{g} / \mathrm{mL}$ for C. albicans ones.

Table 2. MIC ( $\mu \mathrm{g} / \mathrm{mL})$ of Pistacia lenticus L. essential oil against oral microbiota.

\begin{tabular}{ccc}
\hline Strain & Origin & MIC $(\mu \mathrm{g} / \mathbf{m L}$ PLL-EO) \\
\hline Streptococcus gordonii ATCC 10558 & Laboratory & 12.5 \\
Actinomyces naeslundii ATCC 12104 & Laboratory & 3.13 \\
Fusobacterium nucleatum ATCC 25586 & Laboratory & 6.25 \\
Porphyromonas gingivalis ATCC 33277 & Laboratory & 3.13 \\
P. gingivalis BeOR6 & Clinical isolate & 1.63 \\
P. gingivalis BeOR14 & Clinical isolate & 1.63 \\
Tannerella forsythia ATCC 43330 & Laboratory & 3.13 \\
T. forsythia Be13237 & Clinical isolate & 1.63 \\
T. forsythia Be13216 & Clinical isolate & 3.13 \\
Candida albicans ATCC 76615 & Laboratory & 12.5 \\
C. albicans BeT41 & Clinical isolate & 12.5 \\
C. albicans BeT603 & Clinical isolate & 12.5 \\
Candida glabrata DSM 6425 & Laboratory & 6.25 \\
C. glabrata Be10183 & Clinical isolate & 6.25 \\
C. glabrata Be184 & Clinical isolate & 6.25
\end{tabular}

MIC: Minimal Inhibition Concentration; PLL-EO: Pistacia lentiscus L. leaves essential oil. Growth control with distilled water, always confirmed the growth of all the microbial strains in the absence of PLL-EO.

\subsection{Anti-inflammatory Assays}

\subsubsection{COX-1/2 Inhibition}

The anti-inflammatory activity, expressed as a percentage of COX-1/2 inhibition by increasing concentrations of PLL-EO $(1,10$, and $100 \mu \mathrm{g} / \mathrm{mL})$, allowed us to establish the $\mathrm{IC}_{50}$ values. Compared to the control sample (0 PLL-EO), where the COX-1/2 activity was considered equal to $100 \%$ (Figure 1), 
the $\mathrm{IC}_{50}$ values resulted as $10.3 \pm 4.4 \mu \mathrm{g} / \mathrm{mL}$ and $6.1 \pm 2.5 \mu \mathrm{g} / \mathrm{mL}$ for COX-1 and COX-2, respectively. These values were only seven times higher than the $\mathrm{IC}_{50}$ values of the positive control ibuprofen $(1.3 \pm 0.5 \mu \mathrm{g} / \mathrm{mL}$ for COX-1, $0.87 \pm 0.39 \mu \mathrm{g} / \mathrm{mL}$ for COX-2). Thus, the inhibitory activity of PLL-EO toward COX-2 was higher in comparison to that produced toward COX-1, similarly as it was regarding ibuprofen.
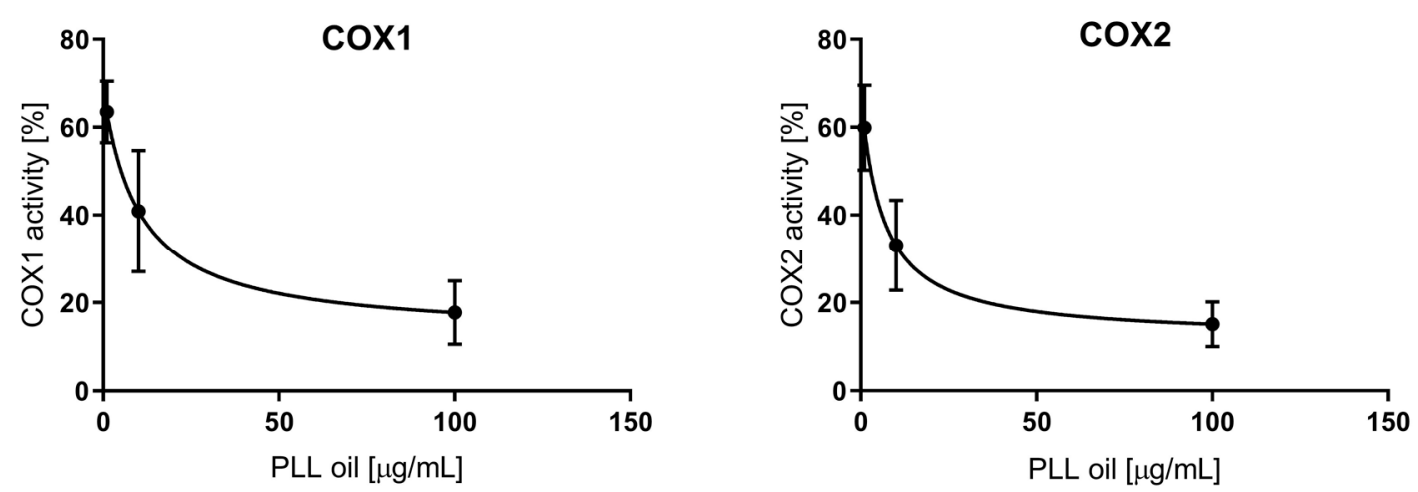

Figure 1. The anti-inflammatory effect of PLL-EO toward cyclooxygenase (COX-1 and COX-2) activity.

\subsubsection{LOX Inhibition}

The measured values were related to a control sample, which represented $100 \%$ enzyme activity, i.e., uninhibited reaction. According to the data (Figure 2), the highest PLL-EO concentration employed $(100 \mu \mathrm{g} / \mathrm{mL})$ did not reach the $\mathrm{IC}_{50}$ value since the activity was lowered by $30 \%$ compared to the control. Thus, PLL-EO showed a weak inhibitory effect toward LOX activity. Phenidone $(100 \mu \mathrm{g} / \mathrm{mL})$ used as positive control inhibited LOX activity by $63.4 \pm 8.6 \%$.

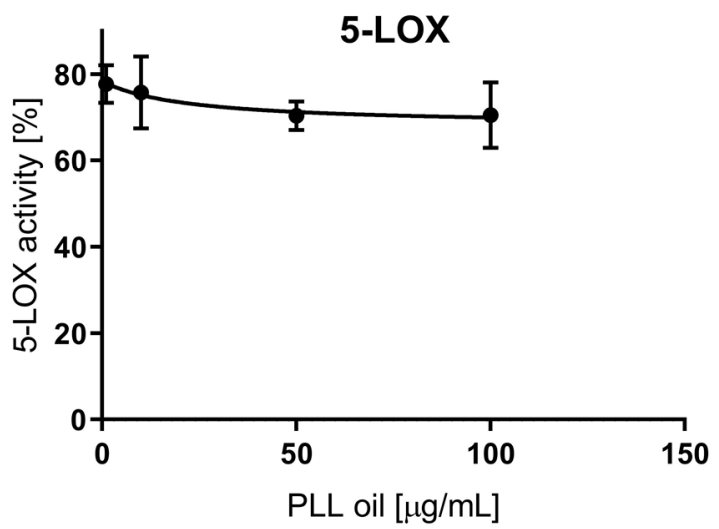

Figure 2. The anti-inflammatory effect of PLL-EO toward soybean lipoxygenase (LOX) activity.

\subsubsection{Electro-Chemical Determination of the Antioxidant Activity}

According to previous studies, the redox potential of $+500 \mathrm{mV}$ is used to detect the antioxidant capacity of phenolic compounds in vegetable matrices, while $+800 \mathrm{mV}$ potential is used to assess the total phenolics content $[37,38]$. A low oxidation potential indicates a high reducing power since the ionization potential is the main factor to determine the efficiency of antioxidants [39]. In Figure 3, the voltammogram of PLL-EO was compared with that of $\alpha$-tocopherol (green line), a well-known antioxidant molecule. The red line indicates PLL-EO oxidation occurred at $+550 \mathrm{mV}$, where it splits the baseline (black line) with an oxidation peak of about $+800 \mathrm{mV}$. Thus, the data suggests a poor antioxidant activity of the hydro-distilled EO. Cyclic voltammetries of PLL-EO main components further accredit this result: $\alpha$-pinene and terpinen-4-ol split the baseline at $+600 \mathrm{mV}$ and $+450 \mathrm{mV}$, 
with peaks at $+720 \mathrm{mV}$ and $+750 \mathrm{mV}$ respectively, while no redox peaks were observed regarding $\alpha$-phellandrene (Figures S1-S3 in Supplementary Material).

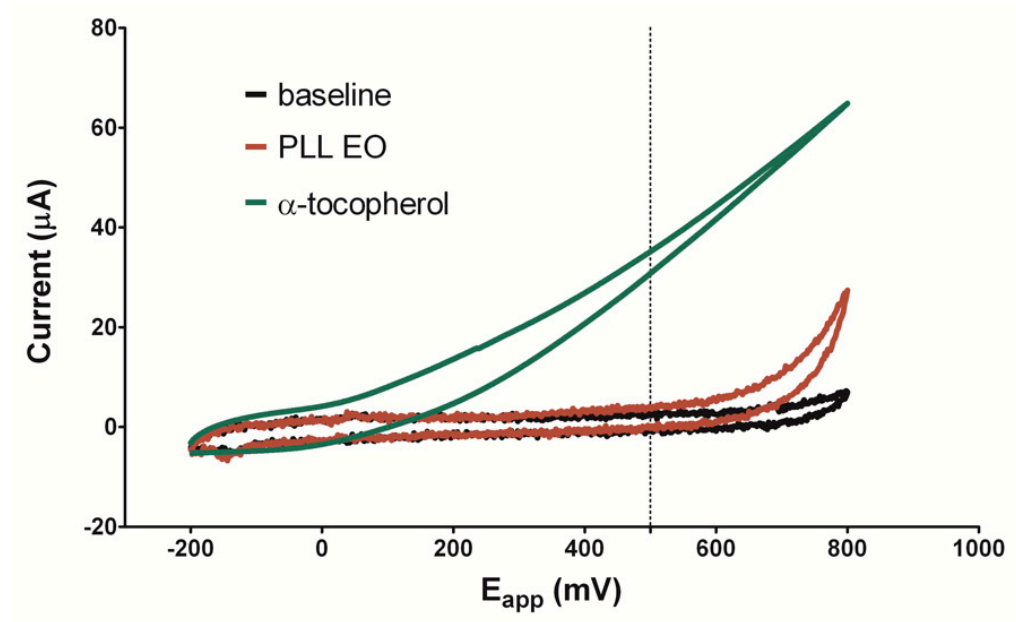

Figure 3. Cyclic voltammetry of PLL-EO with a scanned potential range $\left(\mathrm{E}_{\mathrm{app}}\right)$ between $-200 \mathrm{mV}$ and $+800 \mathrm{mV}$ vs $\mathrm{Ag} / \mathrm{AgCl}$ reference electrode, in the absence (black line) and in the presence of $200 \mathrm{mg} / \mathrm{mL}$ PLL-EO (red line), in comparison with $1 \mathrm{mM} \alpha$-tocopherol (green line).

\subsection{Viability Assay}

The protective effects of PLL EO toward the oxidative stress affecting the GF were evaluated by the MTT assay, testing different concentrations of the oil. The results showed a significant increase in cell viability when GFs were treated with $10,25,50$ and $75 \mu \mathrm{g} / \mathrm{mL}$ of PLL EO in comparison to that observed in the control group and using the DMSO 0.1\%. Differently, the cells subjected to the oxidative stress evidenced a vitality drop of about $30 \%$ in comparison to the control, and when PLL EO was administered before the oxidative stress, no beneficial effects occurred (Figure 4).

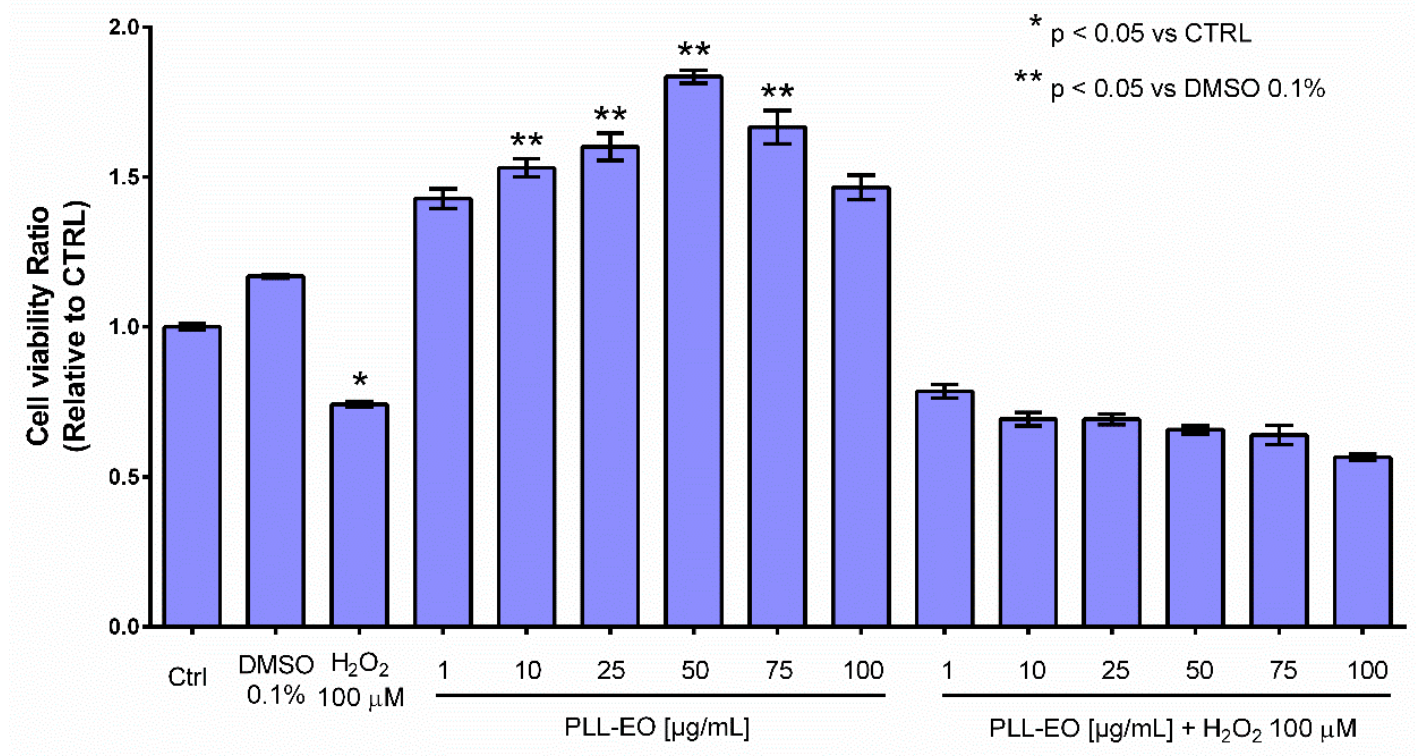

Figure 4. Primary gingival fibroblasts viability relative to the sole growth medium (CTRL), if supplemented with $0.1 \%$ DMSO or $100 \mu \mathrm{M} \mathrm{H}_{2} \mathrm{O}_{2}$ and when amended with PLL-EO $-\mathrm{H}_{2} \mathrm{O}_{2}$ and PLL-EO $+\mathrm{H}_{2} \mathrm{O}_{2}$. The separation of mean values $(\mathrm{n}=4)$ and standard deviation were calculated according to the Student-Newman-Keuls test at $p \leq 0.05$. 


\subsection{Cytotoxicity Assay}

Cytotoxicity effects of increasing concentrations of PLL-EO were recorded for PDLF, GF, GK, and DOK cell lines following a $24 \mathrm{~h}$ incubation. The data did not evidence significant differences $(p<0.05)$ between PLL-EO treated cells and the control. Thus, according to the highest concentration employed in this experiment, it is possible to claim that no toxicity in oral cell lines occurred up to $100 \mu \mathrm{g} / \mathrm{mL}$ of the oil (Figure 5).

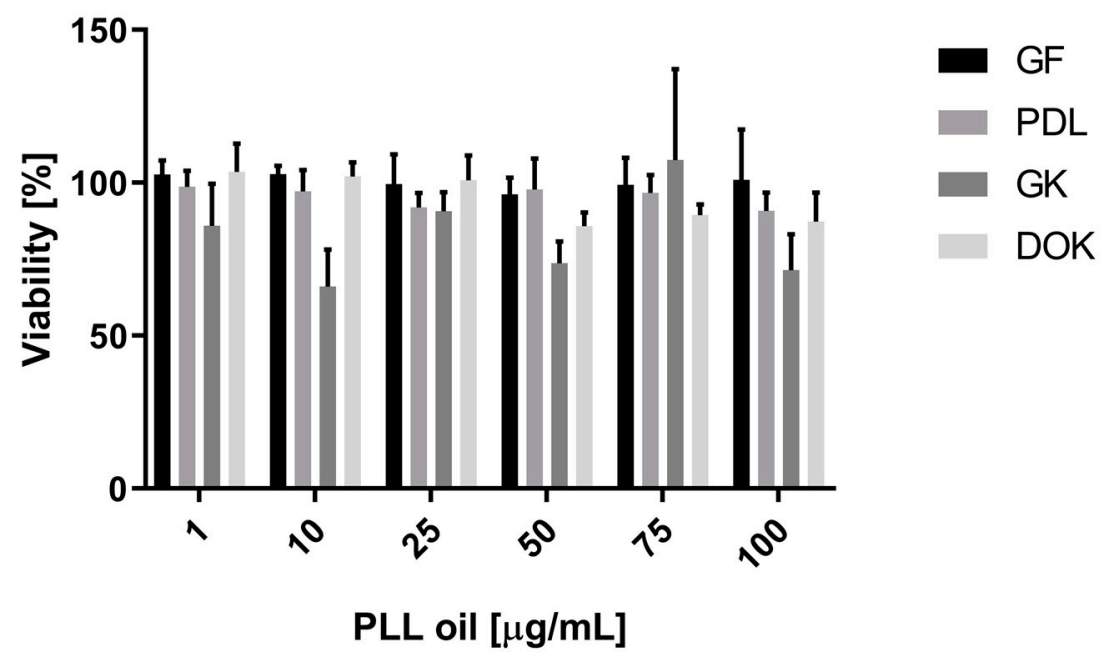

Figure 5. The effect of increasing concentrations of PLL-EO on the viability of human oral cells following $24 \mathrm{~h}$ incubation. GF: gingival fibroblasts; PDLF: periodontal ligament fibroblasts; GK: gingival keratinocytes, and DOK: dysplastic oral keratinocytes. Data (mean from six parallels in three independent experiments \pm S.D.) are expressed as the percentage of viability of untreated cells ( $=100 \%)$.

\section{Discussion}

New treatment options for infections and inflammation should target selectively the pathogens, preventing their ability to form biofilms [40]. Further, they should modulate the host inflammatory response in order to antagonize the accumulation of $\mathrm{PGE}_{2}$ and leukotrienes in chronic inflammatory diseases [11,41]. Moreover, there is a demand for biocompatibility to prevent side effects on the host [21,25]. Natural products are a valuable source of biomolecules that in view of their chemical versatility, offer the possibility to synthesize new drugs containing all of the above-mentioned capacities [14,27-32].

In the present study, we evaluated the peculiar character of PLL essential oil derived from the leaves of wild plants growing in the North of Sardinia. The data demonstrated PLL-EO possesses antimicrobial activity against the tested species in addition to anti-inflammatory properties and high biocompatibility. The antimicrobial capacity was studied by the broth microdilution method, according to the recommendations of EUCAST, in order to compare the data to published reports. Similarly, an enzymatic cell-free in vitro assay using human recombinant COX enzymes and using soybean LOX was carried out to evaluate the inhibitory activity against the most relevant inflammatory mediators [27]. The antioxidant activity was assessed using an electron-chemical method measuring this capacity as the redox properties of the raw oil and the most represented compounds. The electron-chemical system has been credited as a very good device in such a field thanks to the high sensitivity, chemical inertness, and versatility [37-39,42]. In addition, the capacity of selectivity measures the anti-oxidant potency of different fractions in a complex makes the electro-chemical an innovative benchmark method. This is an advantage in comparison to the spectrometric DPPH (2,2-diphenyl-1-picrylhydrazyl) stable assay, which measures the anti-redox potential of the whole pool of compounds in an agent [43]. In addition, the anti ROS effect of the oil was evaluated using GF and the biological MTT method, which is widely applied to ascertain the capability of plant extracts to protect cells of different origins toward $\mathrm{H}_{2} \mathrm{O}_{2}$ stress $[28,44]$. Finally, the biocompatibility was assessed by means of WST-1 metabolic assay using 
four oral cell type lines. The assay allowed us to study the metabolic activity of each cell line after contact with increasing concentrations of PLL-EO, as the viability of mammalian cells grown in culture is largely applied as an indicator of potential toxic effects in animals [44]. In addition, considering that any substance, particularly oral antimicrobials, may potentially come into direct contact with a wide range of cells, we extensively conducted the safety assessment of PLL-EO by testing PDLF, GF, GK, and DOK cells.

PLL is an evergreen environmentally-sustainable shrub, well adapted to harsh growing conditions, dryness, and a warm environment, which all exercise an influence on the genotype [33]. PLL is rich in alternate, leathery leaves, which represent the easiest means to extract the essential oil on a large scale. Thus, the choice to use PLL-EO was aimed to produce highly-repeatable results in view of further researches pointing to novel therapeutic formulations of the oil.

As it has been shown by the GC-MS, the PLL-EO has a high content of terpenes. The most significant fractions were $\alpha$-pinene and terpinen-4-ol constituting 33.38\% of the total EO; furthermore, limonene $(3.89 \%)$ and $\beta$-myrcene $(0.87 \%)$; (Z)-caryophyllene $(1.39 \%)$ and $(\mathrm{E})$-caryophyllene $(0.07 \%)$ were detected (Table 1). These natural compounds are a matter of increasing interest in investigations [31,32] and were recovered in the raw EO in a concentration above $0.05 \%$, which allows us to classify PLL-EO as pharmacologically-active [31]. The chemical composition of PLL-EO depends on the geographical region. Our PLL-EO was high in $\alpha$-pinene and sabinene content when comparing with PLL-EO collected in Turkey [45] or even in other regions of Sardinia [35]. Both $\alpha$-pinene and sabinene were described to exert strong antibacterial activity [46,47], and additionally, $\alpha$-pinene protects cells against oxidative stress [48]. Comparing the chemical profile of the raw EO with that was reported in a previous analysis regarding PLL leaves-EO from Sardinian biodiversity [33], it can be noted that, over time, and regardless of harvesting and seasons, the concentration of such terpenoids has never been lower than $0.05 \%$. Consequently, our data attest to a fairly constant chemical profile of PLL leaves-EO.

The EO exerted antimicrobial activity against all the tested microorganisms (Table 2). It is interesting to note that its activity was higher when compared to that reported in regard to isolated fractions of the oil derived from plants growing in other Mediterranean areas [49,50]. This result can suggest a synergy existing between the pharmacological fractions of terpenes, which characterize the chemotype of PLL-EO we have assessed. High antibacterial activity was found against the reference strains and clinical isolates of $P$. gingivalis and T. forsythia (MICs 1.63-3.13 $\mu \mathrm{g} / \mathrm{mL}$ ). Moreover, the oil exerted activity toward other important species, e.g., F. nucleatum, which is a co-aggregating bacterium in oral biofilms [51], further releasing bone-resorbing pro-inflammatory cytokines and chemokines [10], and to a less extent, toward the commensal S. gordonii. This antimicrobial activity would allow the possible use of PLL to antagonize gingivitis as a primary strategy to prevent periodontitis and a secondary preventive strategy to recurrent periodontitis after periodontal surgery [3].

The possibility to formulate PLL-EO as a potential therapeutic or antiseptic is attractive as testing the viability of GF by the MTT assay, it increased in the presence of the EO in comparison to that observed in the control and DMSO (Figure 4). This evidence can indicate a possible revitalizing ability of the oil toward oral fibroblasts. Our findings are emphasized by the fact that WST-1 did not demonstrate cytotoxicity toward any of the evaluated cell cultures (Figure 5). A safe behavior of PDLF moreover strengthens the use of PLL-EO as an antimicrobial in periodontal disease without interferences in the immune and reparative events, in which fibroblasts are actively involved during the infection [1,10]. Additionally, the biocompatibility with PDLF and GF may put extra emphasis on the capacity of the oil in wound healing because these fibroblasts, as mesenchymal cells, perform important vital functions and are responsible for much of the synthesis of new extracellular matrix during the reparative procedures [1,10]. In regard to the biocompatibility with GK and DOK, it highlights PLL as an antimicrobial with respect for stem cell differentiation and any stimulus toward dysplastic or pre-malignant oral mucosa cells. All these results are appealing, especially because more and more reports have evidenced that synthetic antimicrobials in several oral antiseptics possess cytotoxic effects and suppress the viability of oral cells [19-21]. 
We further demonstrated that the PLL-EO was capable of lowering the activity of COX-2 and LOX enzymes (Figures 1 and 2), which are specifically produced in the course of an active inflammatory process [11,12], like that which is developed during the periodontal infection [1,10]. Our in vitro data is supported by in vivo studies that reported PLL-EO reduced the expression of COX-2 in experimental rats, thus preventing harmful effects connected to eicosanoids accumulation in injury [35].

While the study reported here can suggest that PLL-EO could be considered as a useful phytocomplex to treat causes and effects characterizing the periodontal disease, and in regard for oral cells biocompatibility, the antioxidant activity which resulted was low (Figures 3 and 4). This data seems not to be in accordance with previous reports $[33,35,44]$, which measured the anti-ROS capacity of PLL growing in Sardinia using the DPPH spectrophotometric assay and tested the antioxidant protection of different types of PLL extracts on different cell lines in comparison to those used in the present research. Chemically, disagreement can be explained through the different principles that regulate the measurement of the total quantity of antioxidant molecules: the redox properties of phenolics adopted by the electro-chemical method, and the ability of phenolics to scavenge the radical by the DPPH assay [38]. In addition, the simultaneous measurement of the anti-redox potency of the whole pool of compounds in an agent by the DPPH can lead to overestimation of the antioxidant activity of individual chemical classes [43]. With regard to the antioxidant protection of PLL-EO toward $\mathrm{H}_{2} \mathrm{O}_{2}$ damages in cell cultures, the replay could be different in in vivo experimentations and under different testing conditions [44]. This assumption is supported by the fact that PLL-EO was capable of reducing oxidation in frontal cortex cells of adult Wistar rats submitted to carotid artery obstruction [35]. Thus, this aspect should be further defined in future in vivo and in silico assessments.

Furthermore, PLL-EO evidenced antimicrobial activity against reference strains and clinical isolates of C. albicans and C. glabrata (Table 2). The MIC values of PLL-EO were low against Candida sp., particularly in the case of $C$. glabrata, which is known for its clinical resistance to antimicrobials [52]. In fact, Candida tends to withstand anti-fungal treatments, especially when biofilms are formed. This is probably due to the ability of the yeast to produce a high quantity of fungal $\mathrm{PGE}_{2}$, which also exhibits cross-reactivity with that of the host [9]. The issues are increased because of the side effects of antifungal therapies in humans, which may occur due to the poor ability of the drugs to target selectively the fungal cell [9]. In an attempt to solve the problems connected to the yeast resistance, it was demonstrated that the use of aspirin and other COX inhibitors (i.e., NADPHs), increased the anti-fungal efficacy of some compounds, particularly against biofilm cells [53]. Results suggest that COX-2 inhibitors are able to antagonize the biofilm development, resistance, and invasion of the yeast by lowering the level of $\mathrm{PGE}_{2}$. In a similar way, LOX inhibitors showed activity toward fungal $\mathrm{PGE}_{2}$ in a dose-dependent manner [9]. The finding reported here about PLL-EO inhibitory activity toward COX-2 and LOX may be indicative of its capacity to regulate the aggressiveness of Candida sp. Thus, even if further studies are needed to evaluate the specific activity of the EO towards biofilm development, the low MIC values, in addition to the evidenced impact on the most important inflammatory mediators, should indicate PLL-EO as a good antifungal agent, which acts directly against the yeast and indirectly against its virulence with no oral cytotoxicity. This point will be a matter of our future researches.

\section{Materials and Methods}

\subsection{Chemicals and Abbreviations}

Thiazolyl blue tetrazolium bromide (MTT); isopropanol; streptomycin/penicillin; hydrogen peroxide $\left(\mathrm{H}_{2} \mathrm{O}_{2}\right)$; gentamicin; phosphate-buffered saline (PBS) were obtained from Sigma-Aldrich (Milan, Italy). Dulbecco's modified Eagle's medium (DMEM) and Fetal Bovine Serum (FBS) were purchased from Euroclone S.p.A. (Pero, Milan); dimethyl sulfoxide (DMSO). 


\subsection{Plant Material, Essential Oil Extraction, and GC/MS Characterization}

In October 2017, Pistacia lentiscus leaves (PLL) were harvested from wild plants growing on an acidic-siliceous soil under typical Mediterranean climate conditions (Costa Paradiso-Sardinia, $\left.41^{\circ}-3^{\prime}-21^{\prime \prime} \mathrm{N}, 8^{\circ}-57^{\prime}-14^{\prime \prime} \mathrm{E}\right)$. October was chosen because harvesting at this time of the year allows attaining the highest amount of young-mature metabolic active leaves, before the winter senescence takes place. The collected leaves were immediately cold stored $\left(8^{\circ} \mathrm{C}\right)$, transported to the laboratory, and processed within $24 \mathrm{~h}$. Before extraction, 3-uniform replicates of the leaves were prepared. Then, a 4 h-hydro-distillation took place by a Clevenger-type apparatus, as the method of chose to obtain the EO [54]. Following water removal, the recovered oil fraction termed 'essential oil' (PLL-EO) was stored at $-20{ }^{\circ} \mathrm{C}$ until analyses.

\subsection{Gas Chromatography-Mass Spectrometry (GC-MS) Analysis}

Replicates of the PLL-EO were separately analyzed using a GC (Hewlett-Packard Model 5890A) equipped with a flame ionization detector and fitted with a $60 \mathrm{~m} \times 0.25 \mathrm{~mm}$, thickness $0.25 \mathrm{~mm}$ ZB-5 fused silica capillary column (Phenomenex). The injection port and detector temperature were $280^{\circ} \mathrm{C}$. The column temperature was subjected to a linear rise $\left(5^{\circ} \mathrm{C} / \mathrm{min}\right)$ starting from $50{ }^{\circ} \mathrm{C}$ with 3 halts: 1 min at $135^{\circ} \mathrm{C} ; 5 \mathrm{~min}$ at $225^{\circ} \mathrm{C}$ and a final $10 \mathrm{~min}$ halt at $260^{\circ} \mathrm{C}$. Oil samples of $0.2 \mu \mathrm{L}$ (injection volume) were analyzed, diluted in hexane using 2,6-dimethylphenol as an internal standard. Injection was performed using a split/splitless automatic injector HP 7673 and helium as a carrier gas. Several measurements of peak areas were performed through a HP workstation with a threshold set to 0.00 and peak width to 0.02. Compound quantification was expressed as absolute weight percentage using internal standard response factors (RFs). Since oxygenated compounds have lower detectability than hydrocarbons by the Flame Ionization Detector (FID), detector RFs were determined for key components relative to 2,6-dimethylphenol and assigned to other components on the basis of the functional group and/or structural similarity. For this reason, we have multiplied the obtained data for the following correction factors: hydrocarbons by 1; aldehydes and ketones by 1.24; alcohols by 1.28 and esters by 1.408 .

GC-MS analysis was carried out with an Agilent Technologies model 7820A connected to a MS detector 5977E MSD (Agilent) using the same column and operative conditions described formerly. The column was connected with the ion source of the mass spectrometer. Mass units were monitored from 10 to $900 \mathrm{AMU}$ at $70 \mathrm{eV}$. The identification procedure was carried out exclusively considering peaks ranging from 40 to 900 AMU. Compound identification was based on Rt values and mass spectra comparison with those obtained from authentic samples and/or NIST and Wiley library spectra, or the interpretation of EI-fragmentation of molecules [55].

\subsection{Minimal Inhibitory Concentration Assay}

According to the recommendations of EUCAST, the microbroth dilution technique was used to measure the minimal inhibitory concentration. The inhibitory activity of PPL-EO was tested against Streptococcus gordonii (ATCC 10558); Actinomyces naeslundii (ATCC 12104); F. nucleatum (ATCC 25586); P. gingivalis (ATCC 33277 and two clinical isolates); T. forsythia (ATCC 43330 and two clinical isolates); C. albicans (ATCC 76615 and two clinical isolates) and C. glabrata (DSM 6425 and two clinical isolates). In short, PLL-EO was added in a two-fold dilution series beginning from $200 \mu \mathrm{g} / \mathrm{mL}$. As culture media, Wilkins-Chalgren broth was employed for all bacterial strains except for S. gordonii cultured in an adjusted Mueller-Hinton broth. For Candida sp. the RPMI-medium was used. According to EUCAST, after $18 \mathrm{~h}$ of incubation at optimal growing conditions, MIC was determined visually as the lowest effective concentration of PLL-EO without microbial development. Experiments were made in independent replicates $(n=3)$. A growth control containing distilled water instead of PLL-EO was also included. 


\subsection{Anti-Inflammatory Assays}

\subsubsection{COX-1/2 Inhibition}

To determine the anti-inflammatory activity of $1.0,10.0$, or $100 \mu \mathrm{g} / \mathrm{mL}$ PLL-EO, an enzymatic cell-free in vitro assay using human recombinant cyclooxygenase (COX-1, COX-2) (Sigma-Aldrich; Prague, Czech Republic) was performed [27]. The activity was expressed as the percentage of cyclooxygenase inhibition by PLL-EO compared to untreated samples $(0.0 \mu \mathrm{g} / \mathrm{mL}$ PLL-EO). Briefly, COX-1 (1 unit/reaction) or COX-2 (0.2 unit/reaction) was added to $180 \mu \mathrm{L}$ of the incubation mixture (100 mM Tris buffer $\mathrm{pH}$ 8.0; $5 \mu \mathrm{M}$ porcine hematin; $18 \mathrm{mM}$ L-epinephrine; $50 \mu \mathrm{M} \mathrm{Na} \mathrm{EDDTA}_{2}$ in a 96-well plate. PLL-EO $(1.0,10.0$, and $100 \mu \mathrm{g} / \mathrm{mL})$ was dissolved in ethanol $(10 \mu \mathrm{L})$ and the reaction was started with $10 \mu \mathrm{M}$ arachidonic acid. Ibuprofen $(1.0,10.0$, or $100 \mu \mathrm{g} / \mathrm{mL})$ was used as the positive control. The reaction was stopped after $20 \mathrm{~min}$ by adding formic acid $(10 \%)$. The main product of this reaction, $\mathrm{PGE}_{2}$, was quantified using a $\mathrm{PGE}_{2}$ ELISA kit according to the manufacturer's instructions (Enzo Life Sciences, New York, NY, USA). The absorbance was recorded at $405 \mathrm{~nm}$ (Tecan Infinite M200 microplate reader). Experiments were repeated three times with three technical replicates.

\subsubsection{LOX Inhibition}

An enzymatic cell-free in vitro assay using soybean LOX (Sigma-Aldrich; Prague, Czech Republic) was carried out to test the inhibitory activity of 1.0, 10.0, 50.0, and $100 \mu \mathrm{g} / \mathrm{mL}$ PLL-EO [27]. The activity was expressed as the percentage of inhibition compared to the untreated samples $(0.0 \mu \mathrm{g} / \mathrm{mL}$ PLL-EO). Briefly, the reaction mixture in a 96-well plate was made of LOX (0.8 units); $0.2 \mathrm{M}$ borate buffer pH 8.5 $(190 \mu \mathrm{L})$; PLL-EO $(1.0-100 \mu \mathrm{g} / \mathrm{mL})$ dissolved in ethanol, and linoleic acid $(90 \mu \mathrm{M})$ was added as enzyme substrate to start the reaction. Phenidone $(1.0,10.0,50.0$ and $100 \mu \mathrm{g} / \mathrm{mL})$ was used as the positive control. The inhibitory activity of PLL-EO on LOX was assessed by recording the absorbance of the conjugated diene formed from linoleic acid at $234 \mathrm{~nm}$ (Tecan Infinite M200 microplate reader).

\subsubsection{Antioxidant Activity}

The electro-chemical characterization of PLL-EO was performed according to Barberis et al. 2010 [42] with some modifications, using a four-channel system (eDaQ Quadstat, e-Corder 410 and Echem software, eDAQ Europe Poland) and screen-printed sensors (Metrohm Italiana s.r.l.) consisting of a $4 \mathrm{~mm}$ working electrode (WE), an $\mathrm{Ag} / \mathrm{AgCl}$ reference electrode (Ref) and a carbon counter electrode. Air-bubbled PBS at $\mathrm{pH}=7.4$ was used as a supporting electrolyte. Voltammograms were obtained placing a drop of $70 \mu \mathrm{L}$ solution on the sensor surface. Cyclic voltammetries $(\mathrm{CV})$, carried out in order to investigate the PLL EO electro-chemical behavior at the WE surface vs. the Ag/AgCl Ref, were executed starting from $-200 \mathrm{mV}$ to $+800 \mathrm{mV}$, at a scan rate of $100 \mathrm{mV}$, in the absence (PBS $+1 \%$ DMSO) and in the presence of PLL-EO and $\alpha$-tocopherol, as the reference antioxidant compound. In order to have a $200 \mathrm{mg} / \mathrm{mL}$ oil concentration, a solution of PLL-EO was prepared in PBS containing 1\% DMSO. In addition, CVs of $\alpha$-pinene, terpinen-4-ol and $\alpha$-phellandrene standards (Sigma-Aldrich, Milan, Italy), as the three main represented compounds in the EO, were carried out using the same methodology starting from $-1 \mathrm{~V}$ to $+1 \mathrm{~V}$.

\subsection{Viability Assay}

\subsubsection{Cell origin, Culture, and Treatments}

The research was ethically conducted in accordance with the Declaration of Helsinki. The protocol and informed consent forms were approved by the Ethics Committee at the University of Sassari [n ${ }^{\circ}$ 1000/CE] [56]. Gingival tissues were attained from donors subjected to wisdom teeth surgery at the Department of Surgery of the Dental Unite, University of Sassari, Italy. Donors were healthy subjects, not suffering from periodontitis or other chronic diseases. Patients were carefully informed of the study's purpose, risks, and benefits. Informed consent was obtained from all subjects prior to the study. 
Gingival primary fibroblasts were isolated from the above-mentioned gingival tissue. GF were cultured in Dulbecco's modified Eagle's medium containing 10\% FBS and 1\% penicillin (100 U)/streptomycin $(100 \mu \mathrm{g} / \mathrm{mL})$ at $37^{\circ} \mathrm{C}$ under humidified $5 \% \mathrm{CO}_{2} /$ air. Then, $2 \times 10^{3} \mathrm{GF} / 100 \mu \mathrm{L}$ (2nd-4th passage) were plated in 96-well plates and amended with increasing concentrations of PLL-EO $(0.0,10,25,50,75$ and $100 \mu \mathrm{g} / \mathrm{mL}$ ) dissolved in $0.1 \%$ DMSO. Immediately, plates were returned to the incubator for $24 \mathrm{~h}$. At this time, $100 \mu \mathrm{M} \mathrm{H}_{2} \mathrm{O}_{2}$ was added and the viability was determined by the MTT assay after $140 \mathrm{~min}$. The post-oxidative stress recovery effect of PLL-EO was checked using the same experimental plan with the exception that GF cells were kept first amended with $100 \mu \mathrm{M} \mathrm{H}_{2} \mathrm{O}_{2}$ for $24 \mathrm{~h}$, and then treated with PLL-EO at the given concentrations before performing the MTT assay after $140 \mathrm{~min}$.

\subsubsection{MTT Assay}

GF viability was evaluated by the MTT reduction assay [57]. In short, GF cells were incubated with $100 \mu \mathrm{L}(0.05 \mathrm{mg})$ of MTT for $3 \mathrm{~h}$ at $37^{\circ} \mathrm{C}$. Then, MTT was removed, and the precipitated blue formazan crystals were dissolved in $100 \mu \mathrm{L}$ of isopropanol and the color was read at $570 \mathrm{~nm}$ using a microplate reader (EMax ${ }^{\circledR}$ Plus, Molecular Devices). Cell growth was calculated by normalizing the absorbance of treated cells to the corresponding control. All the experiments were performed in quadruplicate and repeated at least three times.

\subsection{Cytotoxicity Assay}

The WST-1 metabolic activity assay was conducted using PDLF (ScienCell Research Laboratories, Carlsbad, CA, USA, Cat. No. 2620), GF (ScienCell, Cat. No. 2630), GK (The European Collection of Authenticated Cell Cultures - ECACC, Cat. No. PCS-200-014), and DOK (ECACC, Cat. No. 94122104) cells. All cells were seeded in 96-well plates $\left(6 \times 10^{3}\right.$ cells/well $)$ employing DMEM with $10 \%$ heat-inactivated FBS. After $24 \mathrm{~h}$, the culture medium was replaced by the same medium amended by increasing concentrations of PLL-EO $(1.0,10,25,50,75$, and $100 \mu \mathrm{g} / \mathrm{mL})$ dissolved in DMSO $(0.1 \%)$ and ethanol. Control wells were supplemented by the sole medium with $0.1 \%$ DMSO and ethanol. After $24 \mathrm{~h}$ of exposure, the medium was removed, and the cells were rinsed twice with $150 \mu \mathrm{L}$ PBS. Then, according to the manufacturer's instructions, $100 \mu \mathrm{L}$ of culture medium without FBS containing $0.3 \mathrm{mg} / \mathrm{mL}$ cell proliferation reagent WST-1 (Roche, Sigma-Aldrich) was added to each well. Absorbance was measured immediately at 450/650 nm (Tecan Infinite M200 microplate reader) and repeated after $2 \mathrm{~h}$. Metabolic activity of each cell line was assayed in six parallels and in three independent experiments. Viability of the treated cells was expressed as a percentage referred to untreated controls (viability 100\%). The calculations were done using GraphPad Prism 8.1.0 (GraphPad Software, San Diego, CA, USA).

\section{Conclusions}

Herein, we documented the antimicrobial capacity of PLL-EO, which exhibits a broad-spectrum activity against periodontal bacteria and Candida as reference strains and clinical sp., antagonizing them with low MICs. Furthermore, our in vitro study reported that PLL-EO has inhibitory activity toward arachidonic acid oxidative enzymes, specifically proposing the oil as an interesting dual inhibitory agent against COX-2 and LOX. Data suggest a possible role of the EO in the resolution of the inflammatory process, which accompanies periodontal and Candida infections. These facts also sustain that PLL-EO could be a novel antifungal agent that acts directly against the yeast and indirectly against its virulence. All the above-mentioned considerations, further supported by the wide biocompatibility in oral cells, validate our hypothesis and underline the potential of PLL-EO obtained from leaves collected at Costa Paradiso-Sardinia, as an ingredient in oral health-care products for the long-term use. Such oral-health care products may have beneficial effects in periodontal therapy, as they may prevent gingival inflammation and Candida infections, in particular in immune-compromised patients. 
Supplementary Materials: The following are available online at http://www.mdpi.com/2079-6382/9/6/281/s1, Figure S1: Cyclic voltammetry of $\alpha$-pinene, Figure S2: Cyclic voltammetry of terpinen-4-ol, Figure S3: Cyclic voltammetry of $\alpha$-phellandrene.

Author Contributions: Conceptualization, E.M., S.E., B.S., and G.D.; methodology, S.E.; E.M., B.S., M.U. and G.D.; software, V.C. and G.M.; validation, E.M., B.S., G.D. and S.E.; formal analysis, B.S., Y.S., A.B. and M.M.; investigation, M.U., B.S., M.E., V.K., Y.S., A.B., M.M., A.B., L.L., S.E.; data curation, V.C. and G.M.; writing-original draft preparation, E.M., M.U., B.S., Y.S. A.B., and S.E.; writing-review and editing, E.M., B.S., G.D. and S.E. All authors have read and agreed to the published version of the manuscript.

Funding: This research received no external funding. Věra Králová was supported by the project Progres Q40/01 at the Charles University, Faculty of Medicine in Hradec Králové, Czech Republic. Lenka Langhansova was supported by the project LTC17035 Inter-COST granted by Czech Ministry of Education, Youth, and Sports.

Conflicts of Interest: The authors declare no conflict of interest.

\section{References}

1. Papapanou, P.N.; Sanz, M.; Buduneli, N.; Dietrich, T.; Feres, M.; Fine, D.H.; Flemmig, T.F.; Garcia, R.; Giannobile, W.V.; Graziani, F.; et al. Periodontitis: Consensus report of workgroup 2 of the 2017 World Workshop on the Classification of Periodontal and Peri-Implant Diseases and Conditions. J. Periodontol. 2018, 89 (Suppl. 1), S173-S182. [CrossRef] [PubMed]

2. Pinna, R.; Campus, G.; Cumbo, E.; Mura, I.; Milia, E. Xerostomia induced by radiotherapy: An overview of the physio-pathology, clinical evidence and management of the oral damage. Ther. Clin. Risk Manag. 2015, 4, 171-188. [CrossRef] [PubMed]

3. Murakami, S.; Mealey, B.L.; Mariotti, A.; Chapple, I.L.C. Dental plaque-induced gingival conditions. J. Periodontol. 2018, 89 (Suppl. 1), S17-S27.

4. Sharma, A. Virulence mechanisms of Tannerella forsythia. Periodontology 2000, 54, 106-116. [CrossRef]

5. Chukkapalli, S.S.; Rivera-Kweh, M.F.; Velsko, I.M.; Chen, H.; Zheng, D.; Bhattacharyya, I.; Gangula, P.R.; Lucas, A.R.; Kesavalu, L. Chronic oral infection with major periodontal bacteria Tannerella forsythia modulates systemic atherosclerosis risk factors and inflammatory markers. FEMS Path. Dis. 2015, 73, ftv009. [CrossRef] [PubMed]

6. Low, C.Y.; Rotstein, C. Emerging fungal infections in immunocompromised patients. F1000 Med. Rep. 2011, 3, 14. [CrossRef] [PubMed]

7. Scott, S.G. Filler Candida-host cell receptor-ligand interactions. Curr. Opin. Microbiol. 2006, 9, 333-339.

8. Richardson, J.P.; Moyes, D.L.; Ho, J.; Naglik, J.R. Candida innate immunity at the mucosa. Semin. Cell Dev. Biol. 2019, 89, 58-70. [CrossRef]

9. Liu, X.; Wang, D.; Yu, C.; Li, T.; Liu, J.; Sun, S. Potential antifungal targets against a Candida biofilm based on an enzyme in the arachidonic acid cascade-A review. Front. Microbiol. 2016, 7, 1925. [CrossRef]

10. Sanz, M.; Beighton, D.; Curtis, M.A.; Cury, J.A.; Dige, I.; Dommisch, H.; Ellwood, R.; Giacaman, R.A.; Herrera, D.; Herzberg, M.C.; et al. Role of microbial biofilms in the maintenance of oral health and in the development of dental caries and periodontal diseases. Consensus report of group 1 of the Joint EFP/ORCA workshop on the boundaries between caries and periodontal disease. J. Clin. Periodontol. 2017, 44 (Suppl. 18), S5-S11. [CrossRef]

11. Cavaillon, J.M.; Adib-Conquy, M. The Pro-Inflammatory Cytokine Cascade. In Immune Response in the Critically Ill. Update in Intensive Care Medicine; Marshall, J.C., Cohen, J., Eds.; Springer: Berlin/Heidelberg, Germany, 2002; Volume 31, pp. 37-66.

12. Rådmark, O.; Samuelsson, B. 5-Lipoxygenase: Mechanisms of regulation. J. Lipid Res. 2009, 50, S40-S45. [CrossRef] [PubMed]

13. Miguel, M.G. Antioxidant and anti-inflammatory activities of essential oils: A short review. Molecules 2010, 15, 9252-9287. [CrossRef]

14. Valeriani, F.; Protano, C.; Gianfranceschi, G.; Cozza, P.; Campanella, V.; Liguori, G.; Vitali, M.; Divizia, M.; Spica, V.R. Infection control in healthcare settings: Perspectives for mfDNA analysis in monitoring sanitation procedures. BMC Infect. Dis. 2016, 16, 394. [CrossRef] [PubMed]

15. Maida, C.; Campus, G.; Piana, A.; Solinas, G.; Milia, E.; Castiglia, P. Periodontal status in an Italian young adult population. Prevalence and relationship with periodontopathic bacteria. New Microbiol. 2003, 26, 47-56. [PubMed] 
16. Bender, P.; Egger, A.; Westermann, M.; Taudte, N.; Sculean, A.; Potempa, J.; Möllerf, B.; Buchholz, M.; Eick, S. Expression of human and Porphyromonas gingivalis glutaminyl cyclases in periodontitis and rheumatoid arthritis-A pilot study. Arch. Oral Biol. 2019, 97, 223-230. [CrossRef]

17. Campanella, V.; Oberti, L.; Gabrione, F.; González-Valero, L.; Hernández-Martínez, V.; Silvestre-Rangil, J. Periodontitis and cerebrovascular disease: A new novel in medicine. J. Biol. Regul. Homeost. Agents 2019, 33, 135-144.

18. Mummolo, S.; Severino, M.; Campanella, V.; Barlattani, A., Jr.; Quinzi, V.; Marchetti, E. Chlorhexidine gel used as antiseptic in periodontal pockets. J. Biol. Regul. Homeost. Agents 2019, 33, 83-88.

19. Hidalgo, E.; Dominguez, C. Mechanisms underlying chlorhexidine-induced cytotoxicity. Toxicol. In Vitro 2001, 15, 271-276. [CrossRef]

20. Azzimonti, B.; Cochis, A.; El Beyrouthy, M.; Iriti, M.; Uberti, F.; Sorrentino, R.; Landini, M.M.; Rimondini, L.; Varoni, E.M. Essential oil from berries of Lebanese Juniperus excelsa M. Bieb displays similar antibacterial activity to chlorhexidine but higher cytocompatibility with human oral primary cells. Molecules 2015, 20, 9344-9357. [CrossRef]

21. Müller, H.D.; Eick, S.; Moritz, A.; Lussi, A.; Gruber, R. Cytotoxicity and antimicrobial activity of oral rinses in vitro. Biomed. Res. Int. 2017, 2017, 4019723. [CrossRef]

22. Coxib and Traditional NSAID Trialists' (CNT) Collaboration; Bhala, N.; Emberson, J.; Merhi, A.; Abramson, S.; Arber, N.; Baron, J.A.; Bombardier, C.; Cannon, C.; Farkouh, M.E.; et al. Vascular and upper gastrointestinal effects of non-steroidal anti-inflammatory drugs: Meta-analyses of individual participant data from randomised trials. Lancet 2013, 382, 769-779.

23. Clavé, S.; Rousset-Rouvière, C.; Daniel, L.; Tsimarotos, M. The invisible threat of non-steroidal anti-inflammatory drugs for kidneys. Front. Pediatr. 2019, 7, 520. [CrossRef] [PubMed]

24. Blobaum, A.L.; Marnett, L.J. Structural and functional basis of cyclooxygenase inhibition. J. Med. Chem. 2007, 50, 1425-1441. [CrossRef] [PubMed]

25. World Health Organization. Antimicrobial Resistance: Global Report on Surveillance; World Health Organization: Geneva, Switzerland, 2014; ISBN 9789241564748.

26. El-Meleigy, M.A.; Ahmed, M.E.; Arafa, R.A.; Ebrahim, N.A.; El-Kholany, E.E. Cytotoxicity of four oils on some human and bacterial cells. J. Appl. Sci. Environ. Sanit. 2010, 5, 143-159.

27. Langhansova, L.; Landa, P.; Kutil, Z.; Tauchen, J.; Marsik, P.; Rezek, J.; Dong, L.J.; Yun, Z.L.; Vanek, T. Myrica rubra leaves as a potential source of a dual 5-LOX/COX inhibitor. Food Agric. Immunol. 2017, 28, 343-353. [CrossRef]

28. Manconi, M.; Petretto, G.; D’hallewin, G.; Escribanod, E.; Milia, E.; Pinna, R.; Palmieri, A.; Firoznezhadg, M.; Perish, J.E.; Usachh, I.; et al. Thymus essential oil extraction, characterization and incorporation in phospholipid vesicles for the antioxidant/antibacterial treatment of oral cavity diseases. Colloids Surf. B Biointerfaces 2018, 171, 115-122. [CrossRef]

29. Pinna, R.; Filigheddu, E.; Juliano, C.; Palmieri, A.; Manconi, M.; D’hallewin, G.; Petretto, G.; Maioli, M.; Caddeo, C.; Manca, M.L.; et al. Antimicrobial effect of Thymus capitatus and Citrus limon var. pompia as raw extracts and nanovesicles. Pharmaceutics 2019, 11, 234. [CrossRef]

30. Gertsch, J.; Leonti, M.; Raduner, S.; Racz, I.; Chen, J.Z.; Xie, X.Q.; Altmann, K.H.; Karsak, M.; Zimmer, A. Beta caryophyllene is a dietary cannabinoid. Proc. Natl. Acad. Sci. USA 2008, 105, 9099-9104. [CrossRef]

31. Russo, E.B. Taming THC: Potential cannabis synergy and phytocannabinoid- terpenoid entourage effects. Br. J. Pharmacol. 2011, 163, 1344-1364. [CrossRef]

32. Nguyen, L.T.; Myslivečková, Z.; Szotáková, B.; Špičáková, A.; Lněničková, K.; Ambrož, M.; Kubíček, V.; Krasulová, K.; Anzenbacher, P.; Skálová, L. The inhibitory effects of $\beta$-caryophyllene, $\beta$-caryophyllene oxide and $\alpha$-humulene on the activities of the main drug-metabolizing enzymes in rat and human liver in vitro. Chem. Biol. Interact. 2017, 25, 123-128. [CrossRef]

33. Barra, A.; Coroneo, V.; Dessì, S.; Cabras, P.; Angioni, A. Characterization of the volatile constituents in the essential oil of Pistacia lentiscus L. from different origins and its antifungal and antioxidant activity. J. Agric. Food Chem. 2007, 22, 7093-7098. [CrossRef] [PubMed]

34. Di Rosa, A. Erbe e Piante Medicinali in Sardegna, 3rd ed.; Carlo Delfino Ed.: Sassari, Italy, 2018. 
35. Quartu, M.; Serra, M.P.; Boi, M.; Pillolla, G.; Melis, T.; Poddighe, L.; Del Fiacco, M.; Falconieri, D.; Carta, G.; Murru, E.; et al. Effect of acute administration of Pistacia lentiscus L. essential oil on rat cerebral cortex following transient bilateral common carotid artery occlusion. Lipids Health Dis. 2012, 11, 8. [CrossRef] [PubMed]

36. Orrù, G.; Demontis, C.; Mameli, A.; Tuveri, E.; Coni, P.; Pichiri, G.; Coghe, F.; Rosa, A.; Rossi, P.; D’hallewin, G. The selective interaction of Pistacia lentiscus Oil vs. human Streptococci, an old functional food revisited with new tools. Front. Microbiol. 2017, 8, 2067. [CrossRef] [PubMed]

37. Barberis, A.; Spissu, Y.; Bazzu, G.; Fadda, A.; Azara, E.; Sanna, D.; Schirra, M.; Serra, P.A. Development and characterization of an ascorbate oxidase-based sensor-bio-sensor system for telemetric detection of AA and antioxidant capacity in fresh orange juice. Anal. Chem. 2014, 86, 8727-8734. [CrossRef]

38. Buratti, S.; Scampicchio, M.; Giovanelli, G.; Mannino, S. A low-cost and low-tech electrochemical flow system for the evaluation of total phenolic content and antioxidant power of tea infusions. Talanta 2008, 75, 312-316. [CrossRef]

39. Barroso, F.; de lo Santos Alvarez, N.; Delerue-Matos, C.; Oliveira, M.B. Towards a reliable technology for antioxidant capacity and oxidative damage evaluation: Electrochemical (bio) sensors. Biosens. Bioelectron. 2011, 30, 1-12. [CrossRef]

40. Hughes, D.; Andersson, D.I. Evolutionary consequences of drug resistance: Shared principles across diverse targets and organisms. Nat. Rev. Genet. 2015, 16, 459-471. [CrossRef]

41. Joshia, V.; Venkatesha, S.H.; Ramakrishnan, C.; Nanjaraj Urs, A.N.; Hiremath, V.; Moudgil, K.D.; Velmurugan, D.; Vishwanath, B.S. Celastrol modulates inflammation through inhibition of the catalytic activity of mediators of arachidonic acid pathway: Secretory phospholipase A2 group IIA, 5-lipoxygenase and cyclooxygenase-2. Pharmacol. Res. 2016, 113, 265-275. [CrossRef]

42. Barberis, A.; Bazzu, G.; Calia, G.; Puggioni, G.M.; Rocchitta, G.G.; Migheli, R.; Schirra, M.; Desole, M.S.; Serra, P.A. New ultralow-cost telemetric system for a rapid electronchemical detection of vitamin $C$ in fresch orange juice. Anal. Chem. 2010, 82, 5134-5140. [CrossRef]

43. Fadda, A.; Sanna, D. Advantages and pitfalls of the methods for the antioxidant activity evaluation. In Advances in Food Analysis Research; Nova Science Publisher, Inc.: Hauppauge, NY, USA, 2015; pp. 65-88.

44. Bullitta, S.; Piluzza, G.; Manunta, M.D.I. Cell-based and chemical assays of the ability to modulate the production of intracellular Reactive Oxygen Species of eleven Mediterranean plant species related to ethnobotanic traditions. Genet. Resour. Crop Evol. 2013, 60, 403-412. [CrossRef]

45. Duru, M.E.; Cakir, A.; Kordali, S.; Zengin, H.; Harmandar, M.; Izumi, S.; Hirata, T. Chemical composition and antifungal properties of essential oils of three Pistacia species. Fitoterapia 2003, 74, 170-176. [CrossRef]

46. Sharma, S.; Gupta, J.; Prabhakar, P.K.; Gupta, P.; Solanki, P.; Rajput, A. Phytochemical repurposing of natural molecule: Sabinene for identification of novel therapeutic benefits using in silico and in vitro approaches. Assay Drug Dev. Technol. 2019, 17, 339-351. [CrossRef] [PubMed]

47. de Sousa, E.L.; Farias, T.C.; Ferreira, S.B.; Ferreira, P.B.; Lima, Z.N.; Ferreira, S.B. Antibacterial Activity and Time-kill Kinetics of Positive Enantiomer of $\alpha$-pinene Against Strains of Staphylococcus aureus and Escherichia coli. Curr. Top. Med. Chem. 2018, 18, 917-924. [CrossRef] [PubMed]

48. Bouzenna, H.; Hfaiedh, N.; Giroux-Metges, M.A.; Elfeki, A.; Talarmin, H. Potential protective effects of alpha-pinene against cytotoxicity caused by aspirin in the IEC-6 cells. Biomed. Pharmacother. 2017, 93, 961-968. [CrossRef] [PubMed]

49. Turchetti, P.; Pinelli, P.; Buzzini, A.; Romani, D.; Heimler, F.; Franconi, F.; Martini, A. In vitro antimycotic activity of some plant extracts towards yeast and yeast-like strains. Phytother. Res. 2005, 19, 44-49. [CrossRef]

50. Karygianni, L.; Cecere, M.; Argyropoulou, A.; Hellwig, E.; Skaltsounis, A.L.; Wittmer, A.; Tchorz, J.P.; Al-Ahmad, A. Compounds from Olea europaea and Pistacia lentiscus inhibit oral microbial growth. BMC Complement. Altern. Med. 2019, 26, 51. [CrossRef]

51. Tabenski, L.; Maisch, T.; Santarelli, F.; Hiller, K.A. Schmalz Individual growth detection of bacterial species in an in vitro oral polymicrobial biofilm model. Arch. Microbiol. 2014, 196, 819-828. [CrossRef]

52. Rajendran, R.; Sherry, L.; Deshpande, A.; Johnson, E.M.; Hanson, M.F.; Williams, C.; Munro, C.A.; Jones, B.L.; Ramage, G. A prospective surveillance study of Candidaemia: Epidemiology, risk factors, antifungal treatment and outcome in hospitalized patients. Front. Microbiol. 2016, 7, 915. [CrossRef] 
53. Zhou, Y.; Wang, G.; Li, Y.; Liu, Y.; Song, Y.; Zheng, W.; Zhang, N.; Hu, X.; Yan, S.; Jia, J. In vitro interactions between aspirin and amphotericin B against planktonic cells and biofilm cells of Candida albicans and C. parapsilosis. Antimicrob. Agents Chemother. 2012, 56, 3250-3260. [CrossRef]

54. Farmacopea Ufficiale della Repubblica Italiana, 12th ed.; Istituto Poligrafico e Zecca dello Stato: Roma, Italy, 2008.

55. Adams, R.P. Identification of Essential Oil Components by Gas Chromatography/Quadrupole Mass Spectrometry, 3rd ed.; Allured Publ. Corp.: Carol Stream, IL, USA, 2007; pp. 7093-7098.

56. Milia, E.; Castelli, G.; Bortone, A.; Sotgiu, G.; Manunta, A.; Pinna, R.; Gallina, G. Short-term response of three resin-based materials as desensitizing agents under oral environmental exposure. Acta Odontol. Scand. 2013, 71, 599-609. [CrossRef]

57. Ruzza, P.; Siligardi, G.; Hussain, R.; Marchiani, A.; Islami, M.; Bubacco, L.; Delogu, G.; Fabbri, D.; Dettori, M.A.; Sechi, M.; et al. Ceftriaxone blocks the polymerization of $\alpha$-synuclein and exerts neuroprotective effects in vitro. ACS Chem. Neurosci. 2014, 15, 30-38. [CrossRef] [PubMed]

(C) 2020 by the authors. Licensee MDPI, Basel, Switzerland. This article is an open access article distributed under the terms and conditions of the Creative Commons Attribution (CC BY) license (http://creativecommons.org/licenses/by/4.0/). 